\title{
Application of Mobile Technology in Virtual Communities with Information of Conflict-Affected Areas
}

\author{
Julio R. RIBÓN ${ }^{1}$, Luis Javier GARCÍA VILLALBA ${ }^{2}$, Tai-hoon KIM ${ }^{3}$ \\ ${ }^{1}$ Programa de Ingeniería de Sistemas, Facultad de Ingenierías, Universidad de Cartagena, \\ Sede Piedra de Bolívar, Cartagena de Indias, Colombia, \\ E-mail: jrodriguezr@unicartagena.edu.co \\ ${ }^{2}$ Grupo de Análisis, Seguridad y Sistemas (GASS), \\ Departamento de Ingeniería del Software e Inteligencia Artificial (DISIA), \\ Facultad de Informática, Despacho 431, \\ Universidad Complutense de Madrid (UCM), \\ Calle Profesor José García Santesmases s/n, Ciudad Universitaria, 28040 Madrid, Spain, \\ javiergv@fdi.ucm.es \\ 3 Department of Convergence Security, Sungshin Women’s University, \\ 249-1, Dongseon-dong 3-ga, Seoul, 136-742, Korea, \\ taihoonn@empas.com (Corresponding Author)
}

\begin{abstract}
There is a range of organizations which have expertise related to conflict areas (NGOs, governments, etc.). Many of these organizations have put their expertise in digital media that can be accessed by its members through technology platforms. The information in conflict areas is useful for decision making, to generate public policies for the control and humanitarian support. Organizations are willing to cooperate and share their expertise with others, but there is a technological problem that is making the above impossible and therefore causing isolation. This is caused by the inability of the technology platforms that each organization has, to locate and interoperate with expertise from other platforms. This paper describes an experience in which mobile technologies are used as sensing devices to identify positioning and movement of people who are in conflict areas and to capture multimedia information in such territory. These sensing devices allow access to a portfolio of services from a cooperating cloud of territorial information in the region of Montes de Maria (Colombia), which is a territory with political and public order conflicts. With this experience, a solution to the problem of technological isolation is offered and access to the expertise shared by peers in the community.
\end{abstract}

Keywords: Communities, Clouds, Mobile, Territories in Conflicts.

\section{Introduction}

In the territories that present social and public order conflicts, information management and timely access to it, is of vital importance as it contributes to the understanding of the nature of the conflicts that arise. This produces solutions to these, supporting the creation of public policies relevant to the needs of the area, the development of strategies to help the victims of conflicts, the government action plans and the international community, which promote the development of the region.

In conflict areas there is a diversity of communities that are concerned with giving attention to vulnerable population and the development of strategies to resolve the conflict regarding the region, these communities are non-governmental organizations (NGOs), the state through its various entities such as law enforcement (police, army), local authorities (municipalities, ministries, etc..) communities that care for the population (e.g. The Red Cross, hospitals), international organizations and entities who study the conflict such as the universities and researchers in the area, among others.

Each of these communities have been able to gather useful experience for the understanding of the conflict and that is important from their perspective to find solutions to it. These expertise are available to members of each particular community. Recently used for storing digital media and that can be used by each of its members when needed. However, its generally found that such expertise can't be accessed by members of other communities. In many cases communities are unaware of the expertise that others have and can be useful when studying and trying to resolve conflicts in the territory.

Despite the importance of sharing the experience generated in each community, to build a larger organization consisting of multiple cooperating communities, there's a problem of technological isolation which prevents the realization of these collaborative spaces, so that members of virtual communities 
studying conflict zones can locate, share and access the expertise of other peers. This problem is caused by the inability of technology platforms, which each community have, to federate their expertise with other communities, making it impossible to generate a cloud of communities (Chen et al, 2010).

Each technology platform stores the expertise of each community in proprietary formats, which may or may not have standardization initiatives such as SCORM (Advanced Distributed Learning). Ie they are autonomous, heterogeneous platforms, as each one is managed by the Directors of their communities, making it difficult to generate a cloud of communities.

This work contributes to solving the problem through the presentation of a case of studying community integration and service the conflict in the region of Montes de Maria in Colombia (Figure 1), which is a region that has been the victim of conflicts of law and order for years (Abitbol \& Flechas, 2008; United Nations Development Programme) making it difficult for various national and international information which contributes to the generation of strategies to support the solution of such conflicts.

The paper proposes a conceptual model that enables the integration of different communities who have expertise that many communities that study the conflict in the Montes de Maria have. Mobile devices are used as sensors agents (Ying \& Ling \& Latif, 2011; Hii \& Chung, 2011) that allow each of the members of various communities to identify their respective positions in the territory, access relevant information according to location and continue capturing territorial information, becoming members of the communities in the cloud in sensor nodes communities.

This work is useful for all organizations who have common interests in the study and provision of solutions to the conflicts in the territories, allowing them to expand their expertise and insights of it, generate care plans to the conflict according to the reality of the territory, design appropriate plans for the distribution of Humanitarian Aid to the population victim of conflict, assess the nature of the territory, among others.

This work was carried out as follows: initially it is the methodology used for the construction of a cloud of cooperation and the development of a scenario in which mobile nodes sensors function as agents of the communities. Finally the results obtained are discussed and analyzed, to finally draw conclusions.

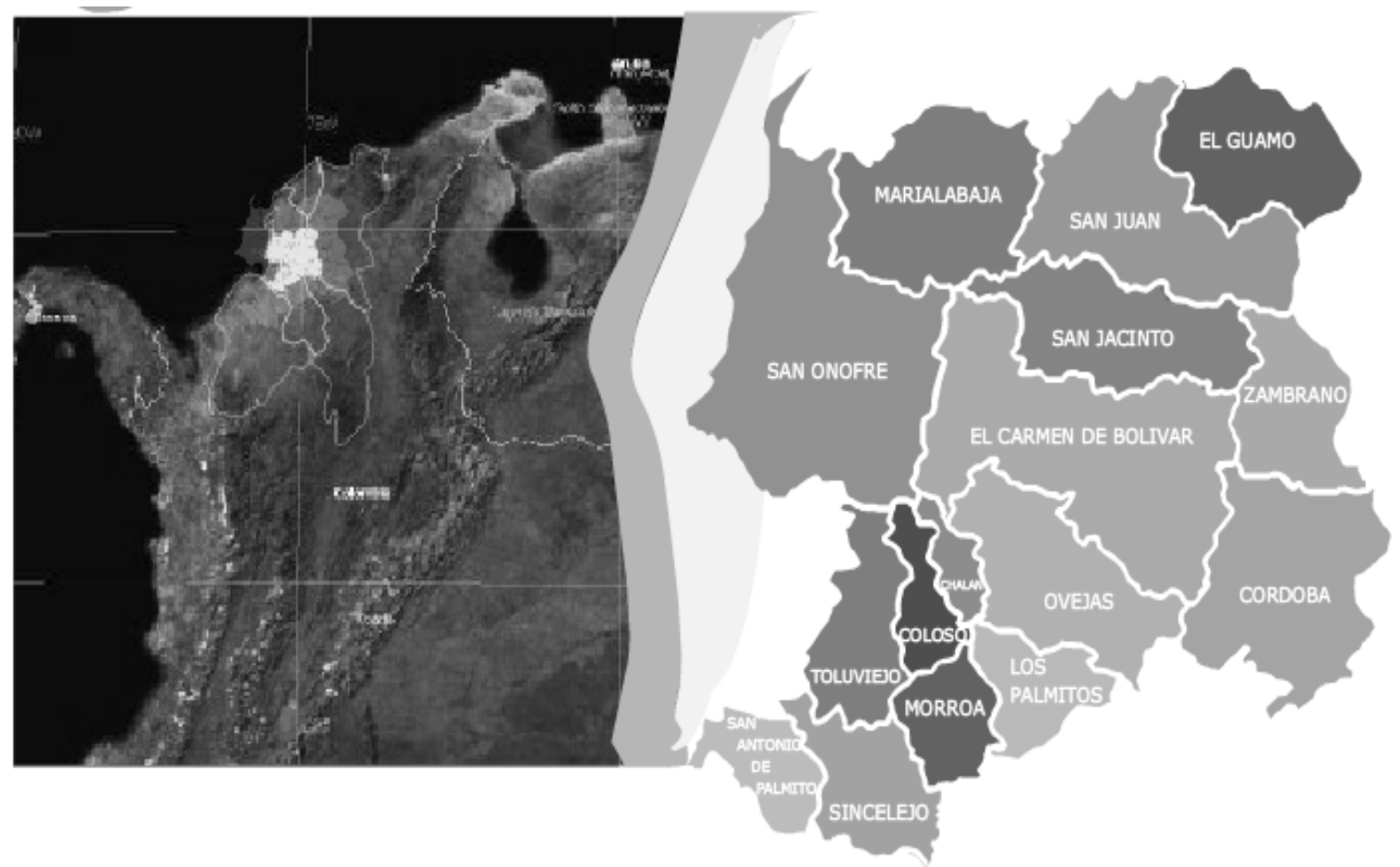

Figure 1. Montes de María (Colombia). 


\section{Material and Methods}

This work is based on a descriptive methodology to characterize and identify various aspects, dimensions or components of the phenomenon to investigate.

The methodology used in the construction of the architectural model is RUP - Rational Unified Process (Booch \& Rumbaugh \& Jacobson, 1999). This methodology was used because it focuses on architecture, which helps to easily connect and integrate processes, methods, techniques and notations in software engineering.

The diagrams used in the description of the architecture are based on UML (Object Management Group, 2007) as modeling language, which is considered a standard in software development.

In the description of the case of study the elements to integrate to form a cloud of communities with territorial information of Montes de Maria are:

1. Moodle: Learning Management System (LMS) that manages the expertise of the community called the University of Cartagena. It is an open source system supported in PHP and MySQL.

2. SITMMA: The Territory System of Montes de Maria. Administered by the Observatory of policy and peace of Montes de Maria. Tool developed on JEE technologies, Argis and Postgress.

3. SICMMA: The Community Information System of Montes de Maria. Administered by the Community Foundation of Montes de Maria. Tool developed on Microsoft Access.

Mobile phones have been used as sensor devices. It uses the mobile device's accelerometer to detect movement and its GPS receiver to identify the geographical position that has a member of the community in the territory. The input and output devices have been used to capture information of the territory, for example the keyboard is used to feed alphanumeric information, and digital camera to capture the territory multimedia information (pictures, videos).

The management software of the mobile node has been implemented using Java Micro Edition technology. For this has been specifically used the API - JSR Application
Programming Interface - JSR 179 and - 256, included in the platform.

To evaluate the performance of the access to the diverse expertise of peers from the sensing devices, it's been proposed a simulated scenery using a network simulator software as a tool, for this has been established the following conditions:

The simulated scenario consists initially of three communities that make up a cloud of cooperation, each server has its content (LMS), which is referenced by a server when the devices PaaS mobile sensors seeking territorial information services, further 3 mobile sensor nodes update and download content from these servers.

Then every 8 seconds, pairs of mobile sensor nodes approach the server which owns the component PaaS with the purpose of updating or downloading content from servers. It is noted that the total simulation time is 40 seconds.

At the end of the simulation a total of 8 nodes have approached, performing service request of territorial information to the server PaaS, which adds overhead to the network.

On the other hand, the objective of the simulation is to determine how they affect QoS metrics in a reference flow (traffic flow in the direction Server1-> Mobile0) as increasing the number of nodes that generate traffic on the network.

Finally it highlights the fact that the bandwidth of each wiring link was 512Kbps and delay of $2 \mathrm{~ms}$.

\section{System Architecture}

An LMS (Nagarajan \& Jiji, 2010; Lonn \& Teasley, 2009) allows the management of learning resources for the various actors who are part of an organization, enabling the formation of a virtual learning community (Alboaie \& Vaida, 2011; Ribón \& de Miguel \& Ortíz, 2009), where the actors interact with each other, to carry activities where they're required and information of territory is captured. For example, academic institutions have LMS applications with documentary information in the territories (geography, hydrography, economics, etc.). The members of the university (Students, Directors, Researchers and Teachers) can establish 
cooperation for the study and proposal of solutions to territorial problems, forming a virtual learning community.

Within the framework of cooperation agreements between institutions, establishing a greater level of aggregation formed with cooperating institution expertise that each brings and makes it accessible to all members of cooperative institutions. This supported in information technology and communications, means that the LMS held by each cooperating institution must interoperate to allow the creation of virtual learning community greater, which enables the sharing of resources contributed by each peer in a cloud of cooperation of territorial information.

In these communities, there may be the same or different LMS technology infrastructure and the same or different storage formats of resources to support the federation of learning resources. In both cases, participants in the federation platforms should be aware of the existence of other federated and offer the actors the chance to interact with the learning resources they have made available to other (enabled learning resources and shared).

In these environments of federation of learning resources, an LMS can continue with its core operations while participating in the federation, i.e. the LMS should enable users to conduct their activities with local learning resources and access to third party information with content created by learning resources that can be stored in different LMS.

In the LMS integration process to form the largest virtual learning community, they must meet requirements that enable the consumption of learning services on demand, i.e. the LMS integration in the cloud attends a serviceoriented business model with low coupling between components.

The following components (Figure 2) allow ondemand consumption of cloud services. Through them runs the collective knowledge of the federation (a cloud of communities).

There are a variety of SaaS platforms that can access the territorial information services for the case treated in architecture and uses two types of SaaS: One described by the LMS in each community, through using a web browser which can access information about the territory, and the other represented through the functionality of mobile devices who serve as sensing devices which identify the location and movement of the members of the community by providing information on where they are and allowing them to capture information of these territories, making mobile SaaS (Figure 3).

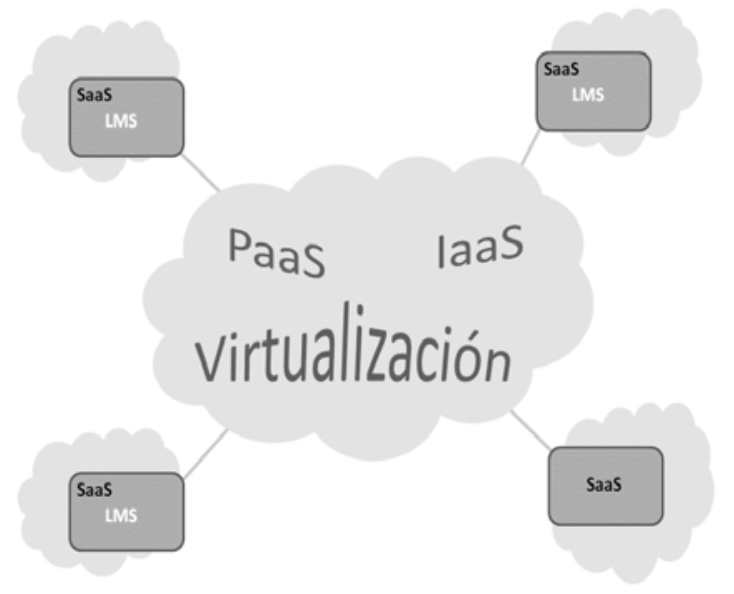

Figure 2. Service-oriented generic model that enables the integration of LMS in a cloud of communities.

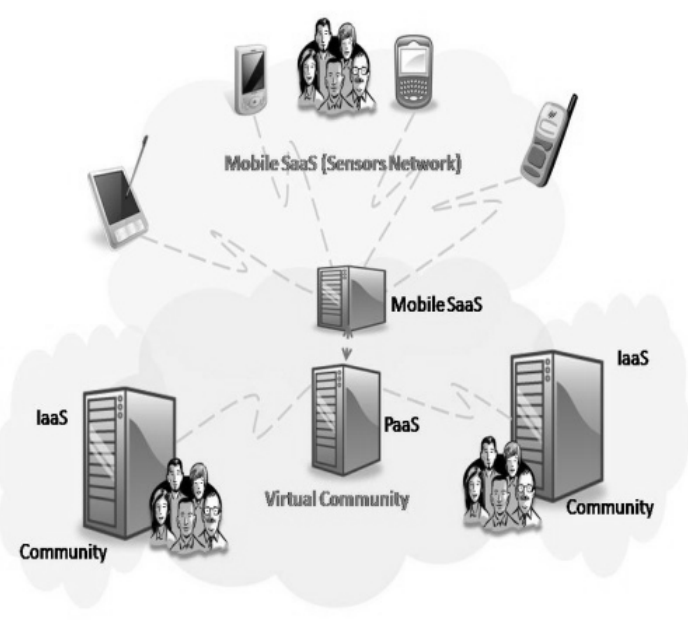

Figure 3. Mobile SaaS (Sensors Network).

\section{Results}

In the region of Montes de Maria there are communities which manage information alluding to the territory. In the case study presented it is examined the contribution made by the following communities:

The University of Cartagena has a Learning Management System (LMS) where learning expertise is placed alluding to the region of Montes de Maria. These expertises are formed by multimedia resources, where there's information referring to the territory, such as 
geographic information, description of land, population data, hydrography and economics, among others.

The Foundation Development and Peace Network of Montes de Maria - FRDPMMa is a Civil Society Organization (CSOs), non-profit, pluralistic, autonomous, participatory and communitarian body that was born to lead and coordinate the Program for Development and Peace in a region hit by violence and high poverty rates within their populations. The foundation has developed a Community Information System of Montes de Maria (SICMMA) under Peace laboratories funded by the European Union.

Another community that studies the region is the Observatory of Political Culture, Peace, Coexistence and Development of Montes de Maria. To fulfill its mission the Observatory has produced a Territorial Information System of the Montes de María - SITMMA, which has geographic information alluding to the region, with which researchers, government and NGOs can support nationally and internationally to meet the reality on the ground and proceed to generate relevant solutions to the reality of the region.

The staff of each of the above communities knows about the information held by the counterparty. It is also difficult to access it when a person is located in one of the municipalities of the territory. In general, researchers from these communities have the ease of updating spatial information when they are in the territory, for example, yielded by environmental disasters or armed conflict, among others, but this task is complicated by the risky situation of territory and the lack of technological means to do such work.

The case study pretends to generate for members of these communities a mechanism to integrate information from SICMMA territorial systems, SITMMA and information held by the University of Cartagena and place accessible to researchers the moment they visit the territory of Montes de Maria.

At the beginning of the case study, communities were willing to cooperate with each other however; the development cooperation process raised the following issues:

- The process of migrating the information that each community has towards other communities, evidenced problems caused by the heterogeneity of the platforms.

- The learning content was updated regularly by the researchers of each community, periodically adding information of the territory, generating consistently implementing the process of migration, which was considered as non-optimal.

- When migrating content to third party organizations, it raises concerns about the protection of intellectual property rights over them.

- Lack of an efficient mechanism to ensure the combination of learning content according to the information needed from each municipality of Montes de Maria.

- Inability of researchers when they are in the territory of real-time access to the information needed, due to lack of technological means.

- Inability of researchers to record information in real time of the contingencies that are detected in the territory.

Because of this, it is decided that these problems could be solved by enabling interoperability between technology platforms owned by each community. Thus they decided to use the methodological guide that provides the architecture proposed in this research.

In Figure 4 there is a description of the implementation of the solution provided by this work. Initially the IaaS component that has been implemented in the architecture was configured, and how to access each local schemes of various technology platforms. Then in a virtual machine it's been designed georeferenced information services, a result of mixing each of the resources shared by federated sources. Finally in mobile SaaS the URL is registered where the component PaaS is located, who ultimately is the one who allows the use of information on demand from the cloud of cooperation, when someone in the cloud needs it.

This allowed the solution to the problems to be presented. In brief they were treated as follows:

- It avoided the migration of expertise of cooperating communities, since the integration of technology platforms allow direct access to learning contents, allowing multiple collaboration scenarios 


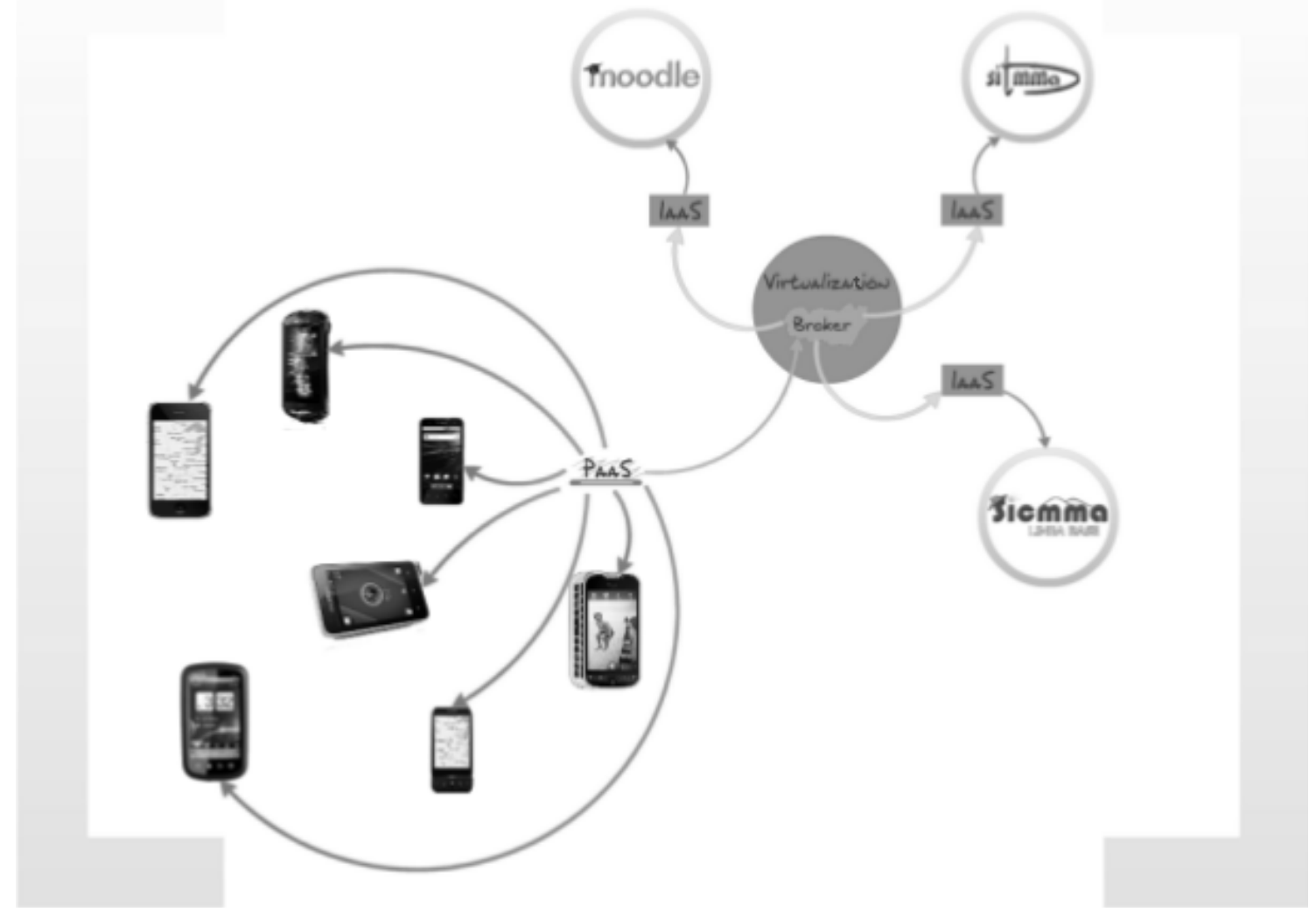

Figure 4. Mobile Devices (Sensors) Accessing Land Information Cloud.

that contemplated the heterogeneity of these systems.

- It could generate constant updates to the learning resources.

- Researchers protected their intellectual property rights on the information provided on the territory.

- Through the exported scheme it was easier to know the resources available to the federation and the descriptors for their access, so as to facilitate the integration of these resources through mobile SaaS.

The architecture also enabled the scalability of content and LMS, in other words, it was possible to build learning content resources formed with other LMS, and also allowed access transparency to users in an LMS, creating through mobile node the sense of that the contents were in the LMS, but really they are stored outside of it, distributed in other systems (Figure 5).

Although the proposed model allows a solution to the problem of technological isolation that prevents the realization of a cloud of cooperation of territorial information of Montes de María, using mobile technologies such as sensing devices, often new sensor nodes appear, because of this the need to assess indicators of quality of service is noticed (QoS), to evaluate the usefulness of the proposed model. Below are the results of the simulation:

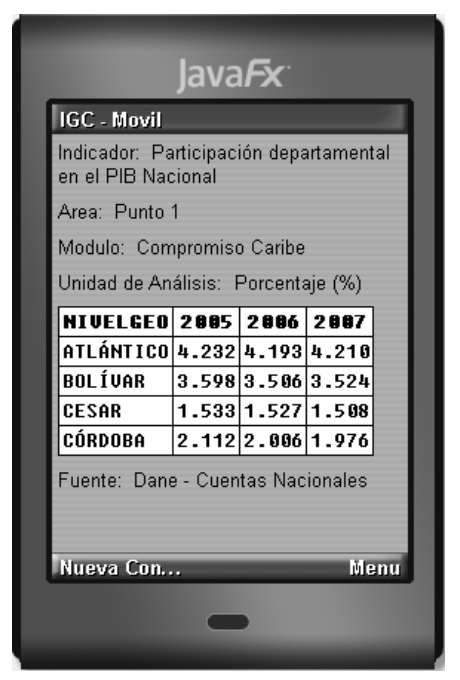

Figure 5. Mobile phone accessing the cloud expertise territory information (information in Spanish).

Initially the sensor Mobile nodes $\{0,1,2\}$ are in the area of the gateway PaaS, then at $t=1.2 \mathrm{~s}$ the Mobile2 start updating content via FTP traffic flow into the server2, then $t=3$.2s initial 
Mobile1 updating the content on server3 with FTP traffic. Then at $\mathrm{t}=4 \mathrm{~s}$ Mobile0 node initiates the download of content from the server1, this traffic type is CBR (video or audio can represent real time or streaming). As they appear on the new cooperating cloud of mobile nodes that are downloading or updating content from the sensing devices, the update or download of content starts from any of the three servers with FTP traffic flow or CBR Thus (Table 1):

Table. 1. Description of Scenarios.

\begin{tabular}{|l|l|l|c|}
\hline $\begin{array}{c}\text { Source } \\
\text { Node }\end{array}$ & $\begin{array}{c}\text { Destiny } \\
\text { Node }\end{array}$ & Traffic & $\begin{array}{c}\text { Time of start of } \\
\text { traffic }\end{array}$ \\
\hline Mobile2 & Server2 & FTP & 1.2 \\
\hline Mobile1 & Server3 & FTP & 3.2 \\
\hline Mobile0 & Server1 & CBR & 4 \\
\hline Server1 & Mobile3 & FTP & 11 \\
\hline Server2 & Mobile4 & FTP & 11 \\
\hline Mobile5 & Server3 & CBR & 18.5 \\
\hline Server1 & Mobile6 & FTP & 25.5 \\
\hline Mobile7 & Server2 & FTP & 26.5 \\
\hline Server3 & Mobile9 & CBR & 33.5 \\
\hline Server1 & Mobile10 & FTP & 35.5 \\
\hline
\end{tabular}

According to the above, the following is the analysis of QoS metrics of the flow of traffic between Server1 (LMS community) and Mobile0 (Sensor).

\subsection{Analysis of delay}

The figure below (Figure 6) illustrates the behavior of delay (delay in the simulation). Initially (Figure 6) at $\mathrm{t}=4 \mathrm{~s}$ the Mobile0 starts downloading content from Server1, at which point the delay experienced is around 2.6s with a downward trend thereafter at $t=13$ s the delay is at its lowest close to 200ms though from $\mathrm{t}=11 \mathrm{~s}$ the Server 1 and 2 provide content to mobile nodes 3 and 4 respectively. In forward despite the presence of new nodes the delay has a regular behavior close to $800 \mathrm{~ms}$. Finally it is noted that the average delay was $797.175 \mathrm{~ms}$ simulation.

\subsection{Analysis of the fluctuation}

The figure below (Figure 7) illustrates the behavior of the jitter of the simulation as time passes. As can be seen (Figure 7) there are four outstanding peaks recorded, of which the last 3 are due to the arrival of new nodes to the gateway area. For the rest of the simulation the

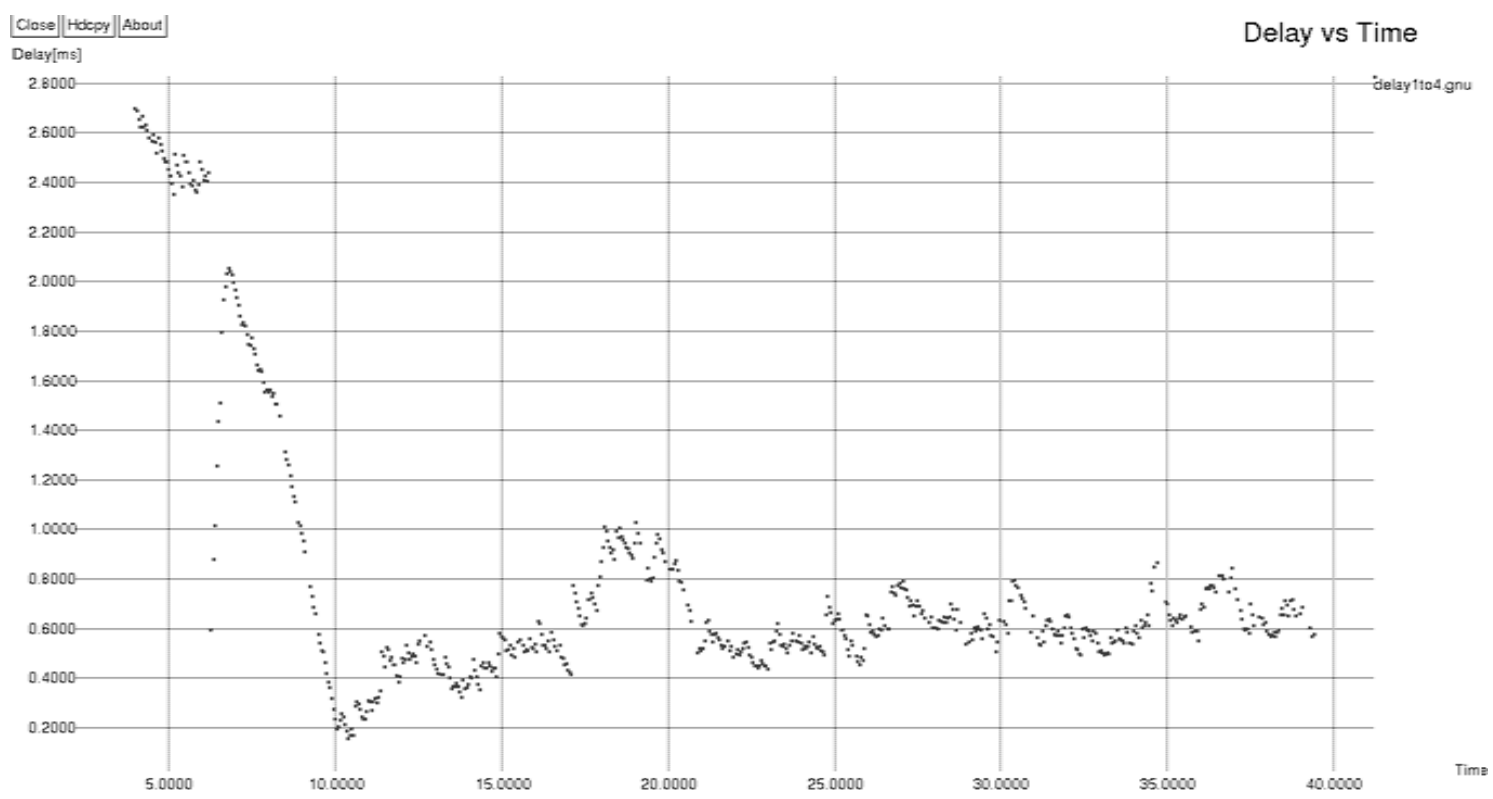

Figure 6. Delay vs Time. 
jitter has a regular behavior close to 20ms. The average jitter was $35.4967 \mathrm{~ms}$.

\subsection{Throughput Analysis}

The figure below (Figure 8) illustrates the behavior of performance as time goes on. As shown in the figure above (Figure 8) before the first two nodes get to the walkway area $(\mathrm{t}=$ $11 \mathrm{~s}$ ) the yield reaches values up to $260 \mathrm{Kbps}$ or so and then it becomes homogeneous around $80 \mathrm{Kbps}$, i.e. as the number of nodes increases the performance decreases to stabilize close to
80Kbps, hereinafter performance is not affected despite the traffic and congestion that is present in the network. The average yield was 59.8625Kbps.

\section{Discussion and Conclusion}

The guidelines proposed in this paper allow multiple scenarios for interoperability between LMS, enabling organizations to share their expertise in a cloud of information related to cooperation in conflict areas, plus it lets them

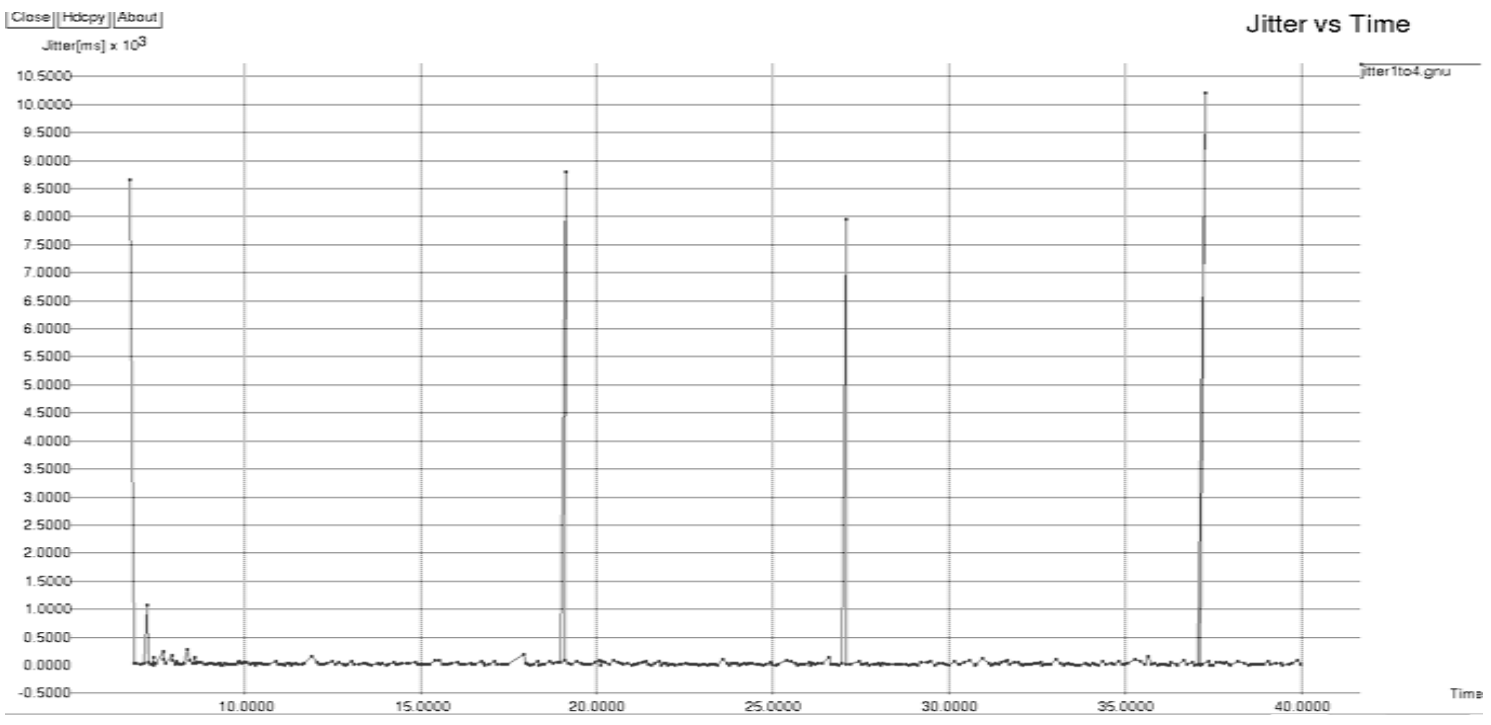

Figure 7. Jitter vs Time.

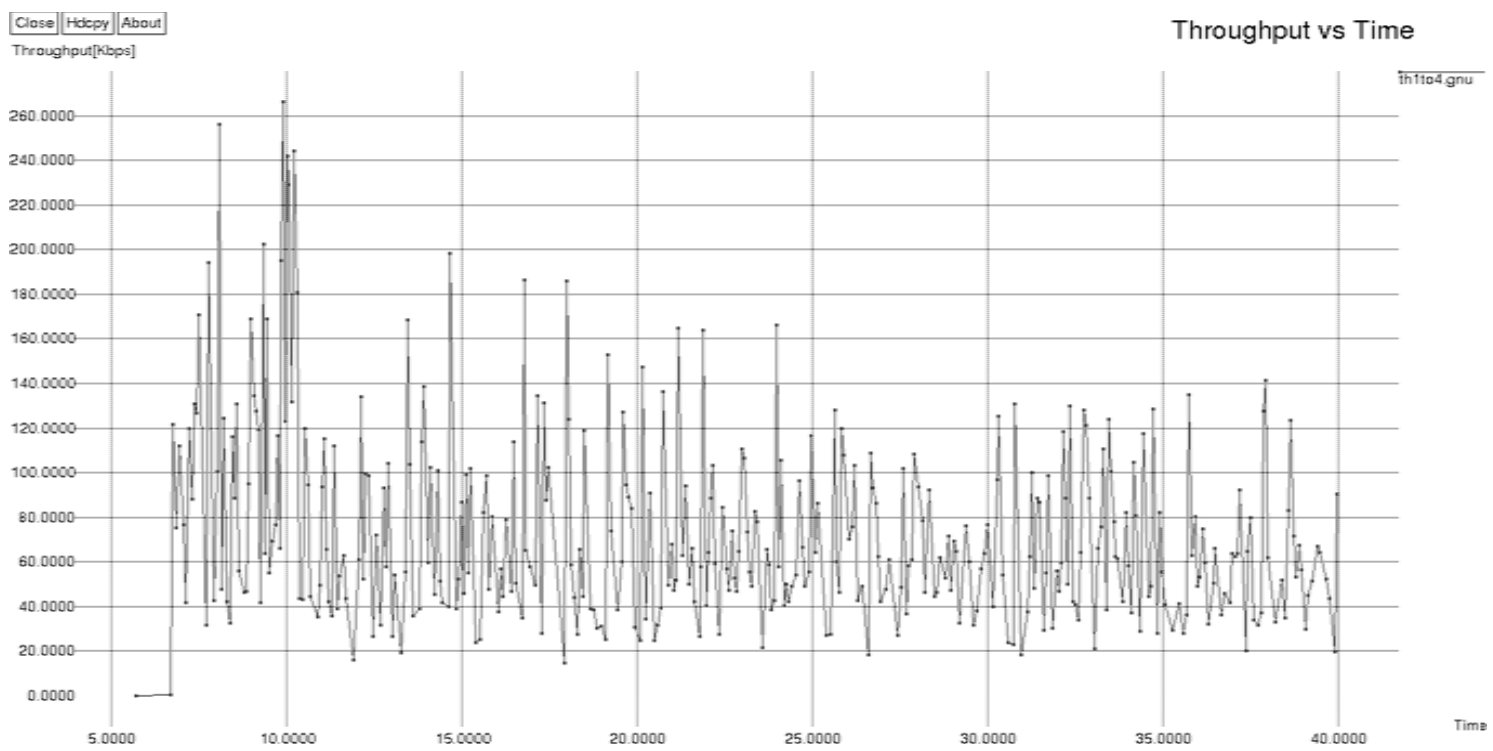

Figure 8. Throughput vs Time 
leverage the use of mobile technologies such as sensor devices that facilitate timely access to shared information in the cloud.

The proposal allows the reuse of code when interoperating with participants in a new LMS e-learning activity, because it implements common functionality components to each system, reducing implementation costs with just indicating in the component connection IaaS the new system federated cooperative.

The model proposed in this work allows the harnessing of the collective intelligence of the masses through the use of content that each organization creates and makes available to other federations. This allows virtual platforms of territorial information to be viewed not only as a technological product, but as service platforms that can be structured through the various learning resources, for example, joint degrees, educational social networks, open communities learning, among other key foundations of Web 2.0.

The proposed model solves the integration of LMS and enables access to learning services through a common interface, such as what is offered by mobile devices, contributing to solving the problem of technological isolation that hinders the creation of virtual communities of learning, due to the heterogeneity of the management and delivery platform for joint degrees in e-learning environments.

On the other hand, the use of mobile nodes such as sensor devices, allows the integration of information alluding to the territory from different sources, enabling the management of that information in a timely manner for the generation of strategies that contribute to the solution of the conflicts that arise in territories such as the Montes de Maria.

\section{Acknowledgements}

This work was supported by the Agencia Española de Cooperación Internacional para el Desarrollo (AECID, Spain) through Acción Integrada MAEC - AECID Mediterráneo A1/037528/11.

\section{REFERENCES}

1. ABITBOL, P., D. FLECHAS, Deliberative Action Arenas on Public Policy Making in Conflict Zones: A Case Study with Women's Groups in Colombia. The Human Development and Capability Association. Annual Conference, New Delhi, 2008, September 10 - 13.

2. Advanced Distributed Learning, http://www.adlnet.gov/Pages/Default.aspx. April 2008.

3. BOOCH G., J. RUMBAUGH, I. JACOBSON, The Unified Software Development Process. Edition 1. Addison Wesley, 1999.

4. CHEN, X., G. B. WILLS, L. GILBERT, D. BACIGALUPO, Using Cloud for Research: A Technical Review. Joint Information Systems Committee (JISC) TeciRes Report. School of Electronic and Computer Science, October 2010.

5. HII, P., W. CHUNG, A Comprehensive Ubiquitous Healthcare Solution on an Android ${ }^{\mathrm{TM}}$ Mobile Device, Sensors 2011, vol. 11(7), 2011, pp. 6799-6815.

6. ALBOAIE, L., M.-F. VAIDA, Trust and Reputation Model for Various Online Communities, Studies in Informatics and Control, vol. 20, issue 2, 2011, pp. 143-156. ISSN 1220-1766.

7. LONN, S., S. D. TEASLEY, Saving Time or Innovating Practice: Investigating Perceptions and Uses of Learning Management Systems. Computers \& Education, vol. 53, issue 3, 2009, pp. 686-694.

8. NAGARAJAN, P. G. W. JIJI, Online Educational System (E- Learning). International Journal of u- and e- Service, Science and Technology, vol. 3, issue 4, 2010, pp. 37-48.

9. Object Management Group - OMG (2007). UML $\quad v \quad$ 2.1.2. Infrastructure Specification and Superstructure Specification. Object Management Group, December 2007. 
10. RIBÓN, J. R., T. P. de MIGUEL, J. H. ORTIZ, Joint Degrees in e-Learning Environments. Proceedings of the 2009 Euro American Conference on Telematics and information Systems: New Opportunities To Increase Digital Citizenship, June 03 - 05 2009; Prague, Czech Republic.
11. United Nations Development Programme, Reduction of Armed Conflict in Colombia Project - Work Report and Projections. (December 2010).

12. YING, S., Y. LING, A. LATIF, EPhone: Embedded Cardiac Care Device in Mobile Phone. Sensor Letters, Volume 9, Number 5, 2011, pp. 1974-1978(5). 